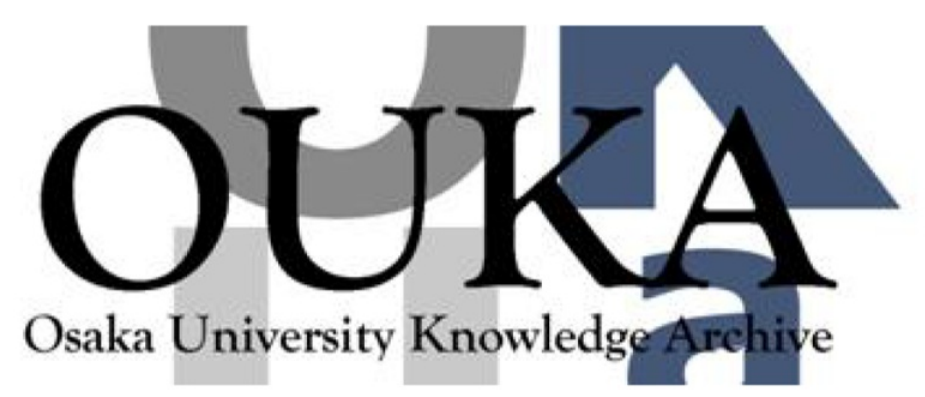

\begin{tabular}{|c|l|}
\hline Title & $\begin{array}{l}\text { Acoustic properties of co-doped ALN thin films } \\
\text { at low temperatures studied by picosecond } \\
\text { ultrasonics }\end{array}$ \\
\hline Author(s) & $\begin{array}{l}\text { Nagakubo, Akira; Arita, Mari; Yokoyama, } \\
\text { Tsuyoshi et al. }\end{array}$ \\
\hline Citation & $\begin{array}{l}\text { Japanese Journal of Applied Physics. 54(7) } \\
\text { p.07HD01-1-p.07HD01-4 }\end{array}$ \\
\hline Issue Date & $2015-05-13$ \\
\hline oaire:version & AM \\
\hline URL & https://hdl. handle. net/11094/84531 \\
\hline rights & ○ 2015 The Japan Society of Applied Physics. \\
\hline Note & \\
\hline
\end{tabular}

Osaka University Knowledge Archive : OUKA

https://ir. Library. osaka-u. ac. jp/

Osaka University 


\title{
Acoustic properties of co-doped AlN thin films at low temperatures studied by picosecond ultrasonics
}

\author{
Akira Nagakubo ${ }^{1}$, Mari Arita ${ }^{1}$, Tsuyoshi Yokoyama ${ }^{2}$, Satoru Matsuda ${ }^{2}$, Masanori UedA ${ }^{2}$, Hirotsugu Ogi ${ }^{1 *}$, \\ and Masahiko HIRAO ${ }^{1}$, \\ ${ }^{1}$ Graduate School of Engineering Science, Osaka University, Toyonaka, Osaka 560-8531, Japan \\ ${ }^{2}$ Taiyo Yuden Co., LTD., Akashi-shi, Hyogo 674-8555, Japan
}

$\left(\mathrm{Mg}_{0.5} \mathrm{Zr}_{0.5}\right)_{x} \mathrm{Al}_{1-x} \mathrm{~N}$ and $\left(\mathrm{Mg}_{0.5} \mathrm{Hf}_{0.5}\right)_{x} \mathrm{Al}_{1-x} \mathrm{~N}$ thin films are AlN-base piezoelectric materials, and their piezoelectric coefficients are higher than those of pure AlN, being promising materials for acoustic devices. However, their acoustic properties remain unknown because of measurement difficulty for deposited thin films. In this study, we measure their longitudinal-wave elastic constants $C_{33}$ and their temperature coefficients using picosecond ultrasound spectroscopy for $0<x<0.13$; we obtain $C_{33}=398.2 \pm 0.7 \mathrm{GPa}$ for pure AlN, and it largely decreases by doping $\mathrm{Mg}$, $\mathrm{Zr}$, and $\mathrm{Hf}$, leading to a minimum values of $316.8 \pm 1.6 \mathrm{GPa}$ for $\left(\mathrm{Mg}_{0.5} \mathrm{Zr}_{0.5}\right)_{0.126} \mathrm{Al}_{0.874} \mathrm{~N}$.

KEYWORDS: Elastic constant, piezoelectric material, temperature coefficient of sound velocity (TCV), AIN

\section{Introduction}

Aluminum nitride (AlN) is an important piezoelectric material and used for film-bulk acoustic resonators (FBARs) in various wireless devices. ${ }^{1-5}$ Although AlN operates at high temperatures, its low piezoelectricity has been desired to be improved. Other group III nitrides and many transition-metal nitrides have been studied for alternative materials because of their outstanding physical properties. Takeuchi, for example, found that there is a metastable wurtzite structure in $\mathrm{ScN}$ and suggested the possibility of fabrication of wurtzite Scdoped AlN using a first-principle calculation. ${ }^{6}$ Akiyama et $a .^{7}$ succeeded in synthesizing wurtzite $\mathrm{Sc}_{x} \mathrm{Al}_{1-x} \mathrm{~N}$ with $x<0.5$ and found that their piezoelectric constants $d_{33}$ were larger than that of AlN at least by a factor 5 . The piezoelectricity enhancement was also confirmed by a first-principle calculation, ${ }^{8}$ and the increment of electromechanical coupling constant for ScAlN was also confirmed in an FBAR. ${ }^{9}$ However, Sc is an expensive element, and it is not suitable for the mass production. Other doping elements have been, therefore, investigated; Yokoyama et al. proposed $\left(\mathrm{Mg}_{0.5} \mathrm{Zr}_{0.5}\right)_{x} \mathrm{Al}_{1-x} \mathrm{~N}$ and $\left(\mathrm{Mg}_{0.5} \mathrm{Hf}_{0.5}\right)_{x} \mathrm{Al}_{1-x} \mathrm{~N}$ and indicated the enhancement in $d_{33}$ by a factor approximately 3 at $x=0.13 .^{10,11}$ However, their important acoustic properties such as sound velocities, elastic constants, and their temperature coefficients remain unclear.

In this study, we measure the longitudinal-wave velocity along $c$-axis $\left(v_{c}\right)$ of $\left(\mathrm{Mg}_{0.5} \mathrm{Zr}_{0.5}\right)_{x} \mathrm{Al}_{1-x} \mathrm{~N}$ and $\left(\mathrm{Mg}_{0.5} \mathrm{Hf}_{0.5}\right)_{x} \mathrm{Al}_{1-x} \mathrm{~N}$ thin films between 190 and $300 \mathrm{~K}$ and their temperature coefficients using picosecond ultrasound spectroscopy. The sound velocity governs resonant frequencies of FBARs, and the temperature coefficient of velocity (TCV) determines the temperature stability of the resonant frequency. Especially, the outof-plane elastic constant $\left(C_{33}\right)$ is the most important parameter in FBARs because it determines the throughthickness resonant frequencies. However, accurate measurement of $C_{33}$ for a thin film is never straightforward; thin films exhibit different mechanical properties from corresponding bulk specimens. ${ }^{12-15}$ Therefore, it is im- portant to measure $C_{33}$ and TCV directly for a deposited thin film, and picosecond ultrasound spectroscopy can measure the out-of-plane sound velocity within $0.5 \%$ accuracy where the film thickness is three times larger than the wavelength. ${ }^{16,17}$ Using this method, we have revealed the elastic properties of oxides films ${ }^{16,17}$ and unusual elasticity of nm-order metallic thin films. ${ }^{18-20}$ In this study, we observe Brillouin oscillation and pulse echo signals within thin films for the same specimens. At room temperature, we determine sound velocity from Brillouin-oscillation method within $0.26 \%$ standard deviation (SD) using measured refractive index by ellipsometry. Measured $C_{33}$ of pure AlN-thin film agrees with the reported bulk value. $C_{33}$ and $Q$ values decrease significantly by doping $\mathrm{Mg}, \mathrm{Zr}$, and Hf elements. Determined TCV of pure AlN thin film from Brillouin-oscillation and pulse-echo methods agree with each other.

\section{Experimental}

We developed the optics for the picosecond ultrasound spectroscopy measurements at cryogenic temperature. $^{21,22}$ We used a Ti/sapphire femtosecond pulse laser whose wavelength, repetition rate, and band width are $800 \mathrm{~nm}, 80 \mathrm{MHz}$, and $7.0 \mathrm{~nm}$, respectively. Using a halfwavelength plate and a polarization beam splitter, we divided the source light pulse into pump and probe light pulses, which excite and detect an ultrasound. We controlled the delay line of the pump light pulse using two corner reflectors and a stage controller, and modulate the pump light pulses as $100 \mathrm{kHz}$ to improve signal-to-noise ratio using a lock-in amplifier. The wavelength $\lambda$ of the probe light is converted into $400 \mathrm{~nm}$ by a second harmonic generator, making it possible to distinguish the pump and probe lights by a dichroic mirror. The pump and probe lights are normally incident to the specimen surface through an objective lens (x20) and the glass window of a cryostat head.

The pump light pulse excites an ultrasharp strain pulse, which propagates in the thickness direction and diffracts the time-delayed probe light pulse backward, leading to interference between the reflected probe light at the surface and the diffracted probe light. The reflec- 


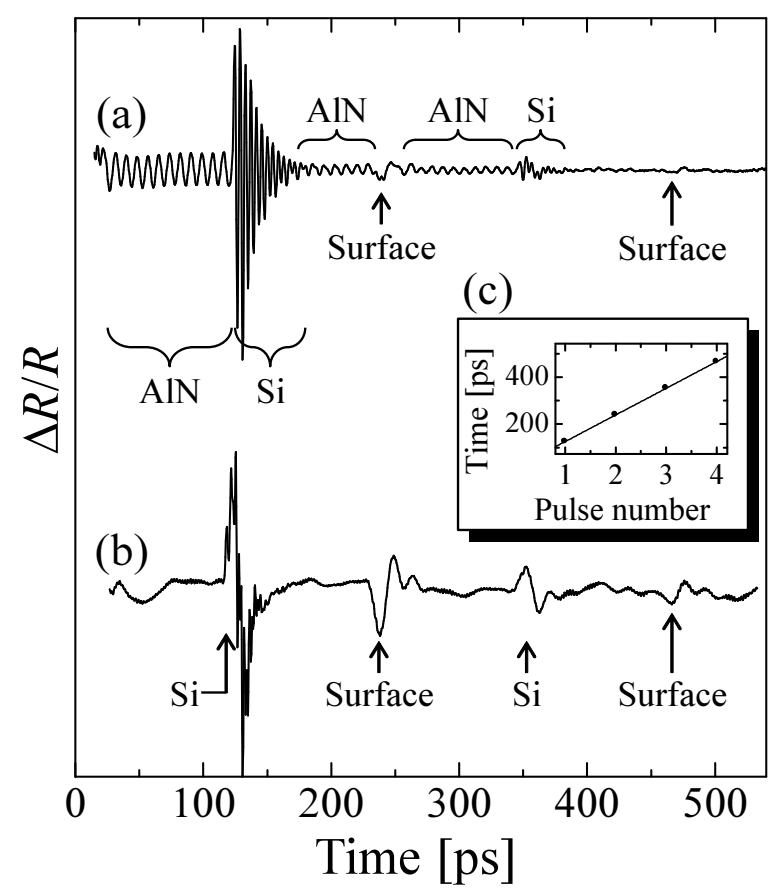

Fig. 1. (a) Observed reflectivity change for the pure AlN specimen and (b) extracted pulse echo using equation (2). We used a polynomial function to extract thermal decay. To determined sound velocity from pulse-echo signals, we used four echoes and calculate the slope as shown in (c).

tivity and the phase of the interference light periodically changes as the ultrasound propagates, which is called Brillouin oscillation, ${ }^{16,17,23}$ and its frequency $f$ is sufficiently expressed by Bragg's diffraction:

$$
f=2 n v_{c} / \lambda
$$

where $n$ and $v_{c}$ are the refractive index and sound velocity of the specimen, respectively. Because the strain pulse can be assumed as a longitudinal plane-wave and the $c$-axis is along the thickness direction, we can obtain the out-of-plane elastic constants $C_{33}=\rho v_{c}^{2}$ using the mass density $\rho$, which is calculated from lattice constants measured by x-ray diffraction for each specimen. We measured $n$ by an ellipsometry method using an instrument V-VASE produced by J. A. Woollam Co.

We prepared a pure AlN thin film, two $\left(\mathrm{Mg}_{0.5} \mathrm{Zr}_{0.5}\right)_{x} \mathrm{Al}_{1-x} \mathrm{~N}$ thin films $(x=0.070$ and $0.126)$, and three $\left(\mathrm{Mg}_{0.5} \mathrm{Hf}_{0.5}\right)_{x} \mathrm{Al}_{1-x} \mathrm{~N}$ thin films $(x=0.058,0.088$, and 0.112$)$ on $\mathrm{Si}(100)$ substrates using radio frequency reactive spattering method. Their film thicknesses are about $1 \mu \mathrm{m}$. Details of the specimens are shown in Table I. We additionally deposited 10-nm Al thin films on the surface as ultrasonic transducers, which convert the pump light pulse into the acoustic pulse.

\section{Results and Discussion}

We show a typical observed signal for the pure AlN thin-film specimen in Fig. 1 (a), where the thermaldecay background was subtracted by a polynomial func-
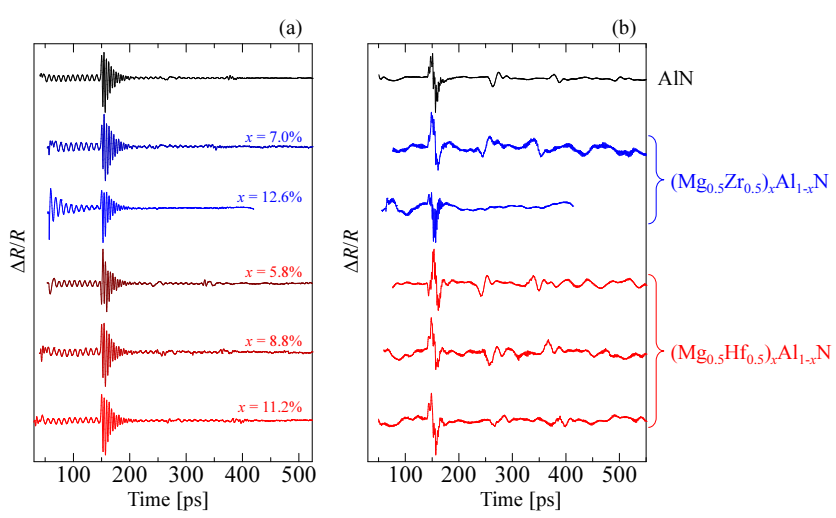

Fig. 2. (Color online) (a) Thermal-decay-free signals and (b) extracted pulse echoes of all specimen measured at room temperature, where the amplitude and delay time were normalized at the Si substrate. The second surface echo can be observed in the pure AlN specimen around 500 ps, but it disappears in doped specimens, insisting that doped elements make the attenuation larger.

tion. The initial small-amplitude and low-attenuation oscillation is the Brillouin oscillation from the AlN thin film. The subsequent high-frequency, larger-amplitude, and higher-attenuation oscillation is that of Si substrate, resulting from higher refractive index, larger piezo-optic constant, and higher extinction coefficient of $\mathrm{Si}$, respectively. We also succeeded in observing the ultrasonic pulse-echo signals around 240 and 470 ps within the thin film, but they are small and buried in the Brillouin oscillations. Therefore, we convert the raw data $S(t)$ into $S^{\prime}(t)$ through the following equation: ${ }^{24}$

$$
S^{\prime}(t)=\frac{1}{4} S\left(t+\frac{\tau}{2}\right)+\frac{1}{2} S(t)+\frac{1}{4} S\left(t-\frac{\tau}{2}\right)
$$

where $\tau$ is the period of a Brillouin oscillation. Using this conversion, we can remove the oscillation component with period $\tau$. To remove both Brillouin oscillations from the thin film and $\mathrm{Si}$, we applied equation (2) twice for $\tau_{\mathrm{AlN}}$ and $\tau_{\mathrm{Si}}$, and obtained the Brillouin-oscillation-free signals as shown in Fig. 1 (b). This signal processing makes the pulse-echo signals clearly visible not only at the surface but also at the film-substrate interface.

We applied this procedures to all specimens as shown in Fig. 2. Except the pure AlN specimen, the secondsurface-echo amplitudes were small despite the same film thickness, insisting that attenuation increases by addition of the substitution elements. We can also confirm this attenuation increment from the Brillouin oscillation from the thin films: its amplitude in pure AlN film appears to be undamped. On the other hand, Brillouinoscillation amplitude of $\left(\mathrm{Mg}_{0.5} \mathrm{Zr}_{0.5}\right)_{0.126} \mathrm{Al}_{0.874} \mathrm{~N}$ film clearly attenuates in 100 ps. Since absorption of probe light in thin films can be neglected for 400-nm wavelength light, ${ }^{25,26}$ attenuation of the Brillouin oscillation is caused by ultrasound attenuation. The $Q$ value of FBARs is also very important especially for a higherfrequency range and we found that it decreases by doping elements; addition of $\mathrm{Mg}$ and $\mathrm{Zr}$ more markedly deteriorates the $Q$ value. We obtained attenuation coefficient of $109 \mathrm{GHz}$ longitudinal wave in $\left(\mathrm{Mg}_{0.5} \mathrm{Zr}_{0.5}\right)_{0.126} \mathrm{Al}_{0.874} \mathrm{~N}$ 
Table I. Measured refractive index $n$, mass density $\rho\left[\mathrm{kg} / \mathrm{m}^{3}\right]$, sound velocity $v_{c}[\mathrm{~m} / \mathrm{s}]$, elastic constant $C_{33}[\mathrm{GPa}]$, and TCV $[\mathrm{ppm} / \mathrm{K}]$ of each thin film.

\begin{tabular}{cccccc}
\hline Specimen & $n$ & $\rho$ & $v_{33}$ & $C_{33}$ & TCV \\
\hline Pure AlN & 2.149 & 3260 & $11052 \pm 10$ & $398.1 \pm 0.7$ & $-50 \pm 9$ \\
$\left(\mathrm{Mg}_{0.5} \mathrm{Zr}_{0.5}\right)_{0.070} \mathrm{Al}_{0.930} \mathrm{~N}$ & 2.240 & 3251 & $9951 \pm 25$ & $321.9 \pm 1.6$ & $-66 \pm 52$ \\
$\left(\mathrm{Mg}_{0.5} \mathrm{Zr}_{0.5}\right)_{0.126} \mathrm{Al}_{0.874} \mathrm{~N}$ & 2.254 & 3349 & $9724 \pm 25$ & $316.7 \pm 1.6$ & $-68 \pm 27$ \\
$\left(\mathrm{Mg}_{0.5} \mathrm{Hf}_{0.5}\right)_{0.058} \mathrm{Al}_{0.942} \mathrm{~N}$ & 2.196 & 3507 & $10041 \pm 26$ & $353.6 \pm 1.9$ & $-50 \pm 23$ \\
$\left(\mathrm{Mg}_{0.5} \mathrm{Hf}_{0.5}\right)_{0.088} \mathrm{Al}_{0.912} \mathrm{~N}$ & 2.201 & 3630 & $9730 \pm 15$ & $343.7 \pm 1.0$ & $-54 \pm 19$ \\
$\left(\mathrm{Mg}_{0.5} \mathrm{Hf}_{0.5}\right)_{0.112} \mathrm{Al}_{0.888} \mathrm{~N}$ & 2.208 & 3737 & $9499 \pm 14$ & $337.2 \pm 1.0$ & $-60 \pm 13$
\end{tabular}

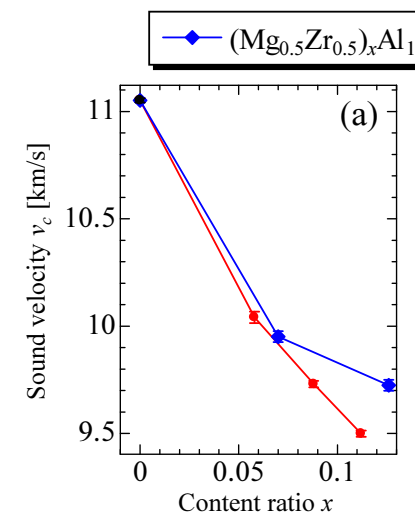

(a)

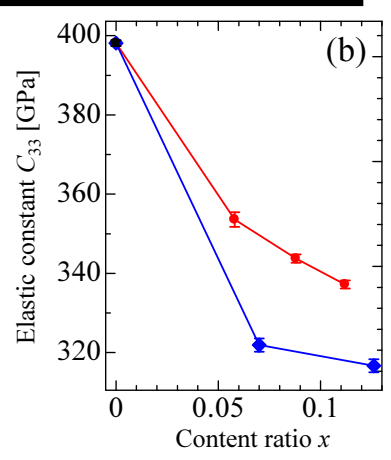

Fig. 3. (Color online) (a) Measured sound velocity $v_{c}$ of all films and (b) elastic constant $C_{33}$. Blue-rhomboid and red-circle symbols denote $\left(\mathrm{Mg}_{0.5} \mathrm{Zr}_{0.5}\right)_{x} \mathrm{Al}_{1-x} \mathrm{~N}$ and $\left(\mathrm{Mg}_{0.5} \mathrm{Hf}_{0.5}\right)_{x} \mathrm{Al}_{1-x} \mathrm{~N}$ thin films, respectively. Although $C_{33}$ of $\left(\mathrm{Mg}_{0.5} \mathrm{Hf}_{0.5}\right)_{x} \mathrm{Al}_{1-x} \mathrm{~N}$ films are higher than $\left(\mathrm{Mg}_{0.5} \mathrm{Zr}_{0.5}\right)_{x} \mathrm{Al}_{1-x} \mathrm{~N}$ films, sound velocity of $\left(\mathrm{Mg}_{0.5} \mathrm{Hf}_{0.5}\right)_{x} \mathrm{Al}_{1-x} \mathrm{~N}$ is smaller than $\left(\mathrm{Mg}_{0.5} \mathrm{Zr}_{0.5}\right)_{x} \mathrm{Al}_{1-x} \mathrm{~N}$, reflecting mass increment due to $\mathrm{Hf}$.

to be $33 \pm 15 \mathrm{~ns}^{-1}$, yielding $2.9 \pm 1.3 \times 10^{5} \mathrm{~dB} / \mathrm{cm}$.

Next, we measured $v_{c}$ and $C_{33}$ of all films from their Brillouin oscillations at room temperature. We measured more than 3 different points on each specimen and determined Brillouin-oscillation frequencies using fast Fourier transformation; their SDs were less than $0.26 \%$. Measured $C_{33}$ and $v_{c}$ are shown in Table I and Fig. 3. Reported $C_{33}$ of pure AlN measured by a Brillouin-scattering method is $402 \mathrm{GPa},{ }^{27}$ showing good agreement with our measurement value of $398.2 \pm 0.7$ GPa. We observed that $C_{33}$ of the co-doped AlN thin films largely decrease (down to $80 \%$ ) and this trend is more remarkable in the $\left(\mathrm{Mg}_{0.5} \mathrm{Zr}_{0.5}\right)_{x} \mathrm{Al}_{1-x} \mathrm{~N}$ films than the $\left(\mathrm{Mg}_{0.5} \mathrm{Hf}_{0.5}\right)_{x} \mathrm{Al}_{1-x} \mathrm{~N}$ films. On the other hand, the sound velocity of $\left(\mathrm{Mg}_{0.5} \mathrm{Hf}_{0.5}\right)_{x} \mathrm{Al}_{1-x} \mathrm{~N}$ is smaller than $\left(\mathrm{Mg}_{0.5} \mathrm{Zr}_{0.5}\right)_{x} \mathrm{Al}_{1-x} \mathrm{~N}$ films, reflecting larger atomic mass of Hf.

Then, we measure TCVs of the films. Brillouinoscillation method is a promising method to measure the longitudinal sound velocity since it does not depend on specimen shape or dimensions. Furthermore, it shows a higher signal-to-noise ratio comparing to Brillouin scattering method due to the excited coherent strain pulse by the pump light pulse. ${ }^{28}$ However, this method requires the refractive index in an analogous way with the Brillouin-scattering method; Watanabe et al. measured refractive index of 9.23- $\mu$ m-thick AlN between 300 and $800 \mathrm{~K}$ and found that refractive index of AlN linearly in-

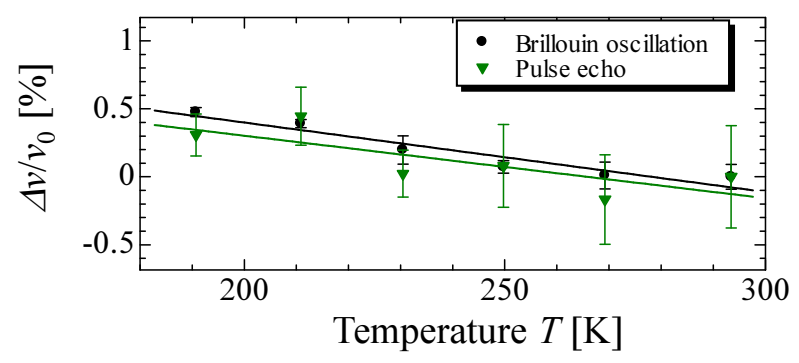

Fig. 4. (Color online) Temperature dependence of sound velocity determined by (black circles) Brillouin-oscillation method and (green triangles) pulse-echo method for the pure AlN thin film. Solid lines show calculated TCV. Although Brillouin-oscillation method shows clearly smaller SD (less than $0.1 \%$ ) comparing to pulse-echo method whose SD is $0.37 \%$ at most, we obtained corresponding TCV values from the two methods, insisting that our measurements and assumption for temperature dependence of refractive index and film thickness is appropriate.

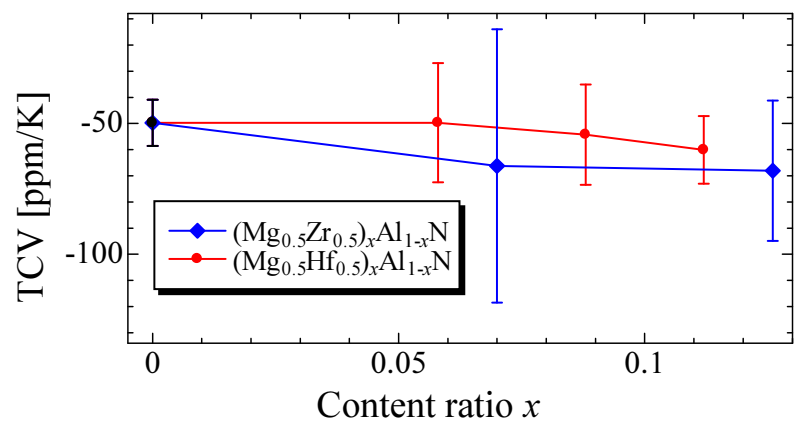

Fig. 5. (Color online) Blue-rhomboid and red-circle symbols denote TCV of $\left(\mathrm{Mg}_{0.5} \mathrm{Zr}_{0.5}\right)_{x} \mathrm{Al}_{1-x} \mathrm{~N}$ and $\left(\mathrm{Mg}_{0.5} \mathrm{Hf}_{0.5}\right)_{x} \mathrm{Al}_{1-x} \mathrm{~N}$ thin films measured from Brillouin oscillation between 190 and $300 \mathrm{~K}$, respectively.

crease with temperature in $38 \mathrm{ppm} / \mathrm{K}$ for $400-\mathrm{nm}$ wavelength light, ${ }^{29}$ and we assumed that $d n / d T$ of all specimens are constant to be $38 \mathrm{ppm} / \mathrm{K}$ between 190 and 300 $\mathrm{K}$. We show the measured temperature dependence of $v_{c}$ of pure AlN thin film in Fig. 4 and obtained TCV of all thin films in Fig. 5. Absolute value of TCV slightly increases by doping $\mathrm{Mg}, \mathrm{Zr}$, and Hf. Measured $v_{c}$ of $\left(\mathrm{Mg}_{0.5} \mathrm{Zr}_{0.5}\right)_{x} \mathrm{Al}_{1-x} \mathrm{~N}$ thin film shows wider distribution $(0.38 \%$ at most $)$, yielding larger error bars of TCV. TCV of $\left(\mathrm{Mg}_{0.5} \mathrm{Zr}_{0.5}\right)_{x} \mathrm{Al}_{1-x} \mathrm{~N}$ and $\left(\mathrm{Mg}_{0.5} \mathrm{Hf}_{0.5}\right)_{x} \mathrm{Al}_{1-x} \mathrm{~N}$ determined by Brillouin-oscillation method should be considered substitution-elements dependence of $d n / d T,{ }^{30}$ how- 
ever, we would obtain same value within our measurements error whether we consider it or not.

We also measured temperature dependence of sound velocity of pure AlN thin film using the pulse-echo method as shown in Fig. 4. Other films prevented us from determining the velocity accurately because of larger attenuation. Thermal expansion coefficients of AlN around room temperature are about $3 \sim 5 \mathrm{ppm} / \mathrm{K},{ }^{31,32}$ and we also estimated Poisson's effect; since AlN thin film and Si substrate have different thermal expansion coefficient, the film thickness changes due to not only thermal expansion of itself but also that of substrate. We assumed that the film is thin enough comparing to the substrate and its in-plane displacements are restricted by the substrate, inducing a thermal strain $\varepsilon_{11}=\left(\alpha^{\mathrm{Si}}-\alpha_{a}^{\mathrm{AlN}}\right) \Delta T$, where $\Delta T$ is temperature change from room temperature, and $\alpha^{\mathrm{Si}}$ and $\alpha_{a}^{\mathrm{AlN}}$ are linear thermal-expansion coefficients of $\mathrm{Si}$ and AlN along $a$-axis, respectively. Then, the total film-thickness change is

$$
\left\{\alpha_{c}^{\mathrm{AlN}}-\frac{2 C_{13}}{C_{33}}\left(\alpha^{\mathrm{Si}}-\alpha_{a}^{\mathrm{AlN}}\right)\right\} d_{0} \Delta T
$$

where $\alpha_{c}^{\text {AlN }}$ is linear thermal-expansion coefficient of AlN along $c$ axis, $C_{13}$ and $C_{33}$ are the elastic constants of AlN, and $d_{0}$ is the film thickness at room temperature, respectively. Equation (3) yields $2.8 \mathrm{ppm} / \mathrm{K}$ at room temperature using reported values. ${ }^{27,31,33}$ We then ignore thermal expansion and determined TCV of pure AlN using the 4 echoes in Fig. 1 (c). We show measured $v_{c}$ in Fig. 4. SD of sound velocity measured by pulse-echo method at each temperature are less than $0.38 \%$. However, they are larger than that measured by Brillouin-oscillation method by a factor 4 for the pure AlN thin film. Determined TCV from Brillouin-oscillation method and pulseecho method are $-50 \pm 9$ and $-46 \pm 34 \mathrm{ppm} / \mathrm{K}$, respectively, and reported temperature coefficient of resonance frequency (TCF) of FBARs is about $-28 \mathrm{ppm} / \mathrm{K} .^{2,34}$ The mean values of TCVs determined by pulse-echo method and Brillouin-oscillation method are comparable, but they are twice larger than the reported TCFs, which are nearly the same as TCVs due to small thermal expansion. The ambiguity of the refractive index might lead to an overestimated our TCVs, while the TCV of AlN in FBAR can not be measured directly, and the indirect estimation is easily affected by temperature behaviors of other components, including buffer layers and electrodes.

\section{Conclusion}

We synthesized $\left(\mathrm{Mg}_{0.5} \mathrm{Zr}_{0.5}\right)_{x} \mathrm{Al}_{1-x} \mathrm{~N} \quad$ and $\left(\mathrm{Mg}_{0.5} \mathrm{Hf}_{0.5}\right)_{x} \mathrm{Al}_{1-x} \mathrm{~N}$ thin films and measured their out-of-plane sound velocity and elastic constant. We succeeded in observing Brillouin oscillations of thin films and pulse-echoes at the same time. Measured $C_{33}$ of pure AlN thin films using Brillouin-oscillation method is comparable to reported bulk value and it largely decreased by doping $\mathrm{Mg}, \mathrm{Zr}$, and $\mathrm{Hf}$. We found that they also decreased $Q$ values and make sound velocity slightly sensitive to temperatures. We obtained TCV of the pure AlN thin film as $=-50 \pm 9 \mathrm{ppm} / \mathrm{K}$ from
Brillouin-oscillation method.

1) P. D. Bradley, R. Ruby, A. Barfknecht, F. Geefay, C. Han, G. Gan, and Y. Oshmyansky: Proc. IEEE Ultrason. Symp. 1 (2002) 931.

2) T. Nishihara, T. Yokoyama, T. Miyashita, and Y. Satoh: Proc. IEEE Ultrason. Symp. 1 (2002) 969.

3) H. P. Loebl, C. Metzmacher, D. N. Peligrad, R. Mauczok, M. Klee, W. Brand, R. F. Milsom, P. Lok, F. V. Straten, A. Tuinhout, and J. W. Lobeek: Proc. IEEE Ultrason. Symp. 1 (2002) 919.

4) F. Matsukura, M. Uematsu, K. Hosaka, and S. Kakio, Jpn. J. Appl. Phys. 52, 07HD02 (2013).

5) F. Matsukura and S. Kakio, Jpn. J. Appl. Phys. 53, 07KD04 (2014).

6) N. Takeuchi: Phys. Rev. B 65 (2002) 045204.

7) M. Akiyama, T. Kamohara, K. Kano, A. Teshigahara, Y. Takeuchi, and N. Kawahara: Adv. Mater. 21 (2009) 593.

8) F. Tasnadi, B. Alling, C. Hoglund, G. Wingqvist, J. Birch, L. Hultman, and I. A. Abrikosov: Phys. Rev. Lett. 104 (2010) 137601.

9) M. Moreira, J. Bjurstrom, I. Katardjev, and V. Yantchev: Vacuum 86 (2011) 23.

10) T. Yokoyama, Y. Iwazaki, Y. Onda, T. Nishihara, and M. Ueda: Proc. IEEE Ultrason. Symp. 1 (2013) 1382.

11) T. Yokoyama, Y. Iwazaki, Y. Onda, Y. Sasajima, T. Nishihara, and M. Ueda: Proc. IEEE Ultrason. Symp. 1 (2014) 281.

12) H. Ogi, M. Fujii, N. Nakamura, T. Yasui, and M. Hirao: Phys. Rev. Lett. 98 (2007) 195503.

13) N. Nakamura, H. Ogi, T. Yasui, M. Fujii, and M. Hirao: Phys. Rev. Lett. 99 (2007) 035502.

14) H. Tanei, N. Nakamura, H. Ogi, M. Hirao, and R. Ikeda: Phys. Rev. Lett. 100 (2008) 016804.

15) K. Tanigaki, H. Ogi, H. Sumiya, K. Kusakabe, N. Nakamura, M. Hirao, and H. Ledbetter: Nat. Commun. 4 (2013) 2343.

16) H. Ogi, T. Shagawa, N. Nakamura, M. Hirao, H. Odaka, and N. Kihara: Jpn. J. Appl. Phys. 48 (2009) 07GA01.

17) H. Ogi, T. Shagawa, N. Nakamura, M. Hirao, H. Odaka, and N. Kihara: Phys. Rev. B 78 (2008) 134204.

18) H. Tanei, N. Nakamura, Y. Kake, H. Ogi, K. Kusakabe, and M. Hirao: Jpn. J. Appl. Phys. 47 (2008) 3847.

19) N. Nakamura, A. Uranishi, M. Wakita, H. Ogi, and M. Hirao: Jpn. J. Appl. Phys. 49 (2010) 07HB04.

20) N. Nakamura, Y. Nakamichi, H. Ogi, M. Hirao, and M. Nishiyama: Jpn. J. Appl. Phys. 52 (2013) 07HB05.

21) K. Tanigaki, T. Kusumoto, H. Ogi, N. Nakamura, and M. Hirao: Jpn. J. Appl. Phys. 49 (2010) 07HB01.

$22)$ A. Nagakubo, A. Yamamoto, K. Tanigaki, H. Ogi, N. Nakamura, and M. Hirao: Jpn. J. Appl. Phys. 51 (2012) 07GA09.

23) A. Devos and R. Cote: Phys. Rev. B 70 (2004) 125208.

24) F. Yang, T. J. Grimsley, S. Che, G. A. Antonelli, H. J. Maris, and A. V. Nurmikko: J. Appl. Phys. 107 (2010) 103537.

25) H. Demiryont, L. R. Thompson, and G. J. Collins: Appl. Optics 25 (1986) 1311.

26) H. Y. Joo, H. J. Kim, S. J. Kim, and S. Y. Kim: Appl. Optics 17 (1999) 862.

27) M. Kazan, E. Moussaed, R. Nader, and P. Masri: Phys. Status Solidi C 4 (2007) 204.

28) A. Nagakubo, H. Ogi, H. Sumiya, K. Kusakabe, and M. Hirao: Appl. Phys. Lett. $102(2013) 241909$.

29) N. Watanabe, T. Kimoto, and J. Suda: J. Appl. Phys. 104 (2008) 106101.

30) U. Tisch, B. Meyler, O. Katz, E. Finkman, and J. Salzman: J. Appl. Phys. 89 (2001) 2676.

31) S. Figge, H. Kroncke, D. Hommel, and B. M. Epelbaum: Appl. Phys. Lett. 94 (2009) 101915.

32) W. M. Yim and R. J. Paff: J. Appl. Phys. 45 (1974) 1456.

33) D. N. Batchelder and R. O. Simmons: J. Chem. Phys. 41 (1964) 2324.

34) T. Yanagitani and M. Suzuki: Appl. Phys. Lett. 105 (2014) 122907. 